\title{
24-h blood pressure and autonomic function is related to albumin excretion within the normoalbuminuric range in IDDM patients
}

\author{
P.L. Poulsen, E . E bbehøj, K. W. H ansen, C. E . M ogensen \\ Medical Department M, (Diabetes and Endocrinology), Aarhus Kommunehospital, Aarhus, Denmark
}

Summary Significant changes in both blood pressure, autonomic function and kidney ultrastructure are observed in insulin-dependent diabetic (IDDM) patients with microalbuminuria. Intervention strategies are evaluated at even earlier stages of disease. Identification of patients at risk of developing microalbuminuria must be based on a thorough knowledge of the relations between key pathophysiological parameters in patients with normoalbuminuria. The aim of the present study was to characterize the interactions of urinary albumin excretion (UAE), 24-h ambulatory blood pressure (AMBP), and sympathovagal balance in a large group of normoalbuminuric IDDM patients. In 117 normoalbuminuric (UAE $<20 \mu \mathrm{g} / \mathrm{min}$ ) patients we performed 24-h AMBP (Spacelabs 90207), with assessment of diurnal blood pressure and heart rate (HR) variation, and short-term (three times $5 \mathrm{~min}$ ) power spectral analysis of RR interval oscillations, as well as cardiovascular reflex tests (HR variation to deep breathing, postural HR and blood pressure response). Patients with UAE above the median $(4.2 \mu \mathrm{g} / \mathrm{min})$ had significantly higher 24-h systolic and diastolic AMBP $(125 \pm 10.1 / 76 \pm 7.2 \mathrm{mmHg}$ ) compared to the low normoalbuminuric group $(120 \pm 8.4 / 74 \pm 5.1 \mathrm{mmHg})$, $p<0.01$ and 0.02 , respectively. Patients with UAE above the median had significantly reduced short-term RR interval variability including both the high frequency component $(5.47 \pm 1.36$ vs $6.10 \pm 1.43$ $\left.\ln \mathrm{ms}^{2}\right)$, and low frequency component $(5.48 \pm 1.18 \mathrm{ln}$ $\mathrm{ms}^{2}$ compared to $\left.5.80 \pm 1.41 \mathrm{ln} \mathrm{ms}^{2}\right), \mathrm{p}<0.02$ and $p=0.04$ (ANOVA). In addition, patients with highnormal UAE had reduced mean RR level (faster heart rates) $916 \pm 108$ compared to $963 \pm 140 \mathrm{~ms}$, $p<0.04$. These differences were not explained by age, duration of diabetes, gender, level of physical activity, or cigarette smoking. $\mathrm{HbA}_{1 \mathrm{c}}$ was significantly higher $(8.6 \pm 1.2$ vs $8.2 \pm 1.0 \%, p=0.03)$ in the group with high normal UAE. Comparing normoalbuminuric IDDM patients with UAE above and below the median value, we found significantly higher AMBP in combination with significant differences in sympathovagal balance and significantly poorer glycaemic control in the group with high-normal albumin excretion. Our data demonstrate interactions between albumin excretion, blood pressure, autonomic function, and glycaemic status, already present in the normoalbuminuric range and may describe a syndrome indicative of later complications. [Diabetologia (1997) 40: 718-725]

Keywords Ambulatory blood pressure, autonomic control, heart rate variability, spectral analysis, IDDM, microalbuminuria, diabetic nephropathy
Received: 9 January 1997 and in revised form: 12 March 1997

Corresponding author: P.L. Poulsen, Department of Medicine M (Diabetes and Endocrinology), Aarhus Kommunehospital, DK-8000 Aarhus C, Denmark
A bbreviations: AMBP, Ambulatory blood pressure; CCV HF, coefficient of component variance $\mathrm{HF}$; CCV LF, coefficient of component variance LF; MSSD, mean square of successive R$\mathrm{R}$ differences; N/D ratio, night/day ratio; Power HF, high frequency power $(0.15-0.50 \mathrm{~Hz})$; Power LF, low frequency power (0.05-0.15 Hz); UAE, urinary albumin excretion; IDDM, insulin-dependent diabetes mellitus. 
The presence of microalbuminuria in insulin-dependent diabetes mellitus (IDDM) patients is a strong predictor of subsequent development of nephropathy [1-3]. Whereas renal function is preserved at this stage, recent data indicate that substantial pathophysiological changes have taken place: in microalbuminuric patients blood pressure is elevated [4-7] with an attenuated circadian rhythm [8]. Vagal function is impaired with an abnormal sympathovagal interaction $[9,10]$. In addition, new ultrastructural findings $[11$, 12] indicate the presence of glomerular and arteriolar abnormalities in IDDM patients with incipient nephropathy. Prevention of progression to microalbuminuria would thus be a major clinical turning-point. A sound description of the relationship between urinary albumin excretion, blood pressure, and autonomic function in normoalbuminuric patients is a prerequisite for the identification of patients at increased risk of developing microalbuminuria.

Spontaneous beat-to-beat fluctuations in heart rate reflect ongoing modulation of sinus node activity through several cardiovascular control mechanisms. Quantification of fluctuations in RR intervals can be used to assess autonomic function [13], and based on 24-h recordings these measurements have proven to be more sensitive than ordinary bedside tests in the detection of early autonomic neuropathy $[9,14,15]$. The application of power spectral analysis, which calculates the frequency content of time varying signals, has provided a powerful tool in the assessment of sympathovagal balance $[16,17]$. This technique permits the identification of two major components with different frequency bands: the respiratory dependent high frequency (HF; $0.15-0.50 \mathrm{~Hz}$ ) oscillations are mediated purely by vagal activity $[16,18]$. The power in this band is highest in the supine position $[16,17,19]$, reduced in upright position, and abolished by atropine $[16,18]$. The power of the HF component is linearly related to pharmacologically determined vagal activity [18]. Low frequency (LF) oscillations in the $0.05-0.15 \mathrm{~Hz}$ band are in the supine position highly dependent on vagal activity, whereas the LF oscillations in the upright position are mediated by interaction between sympathetic and vagal activity $[16,18]$. The spectral power of the HF and LF component can be estimated in 5-min RR interval segments [16-18].

Attenuated circadian blood pressure rhythm with reduced night-time drop is a pathophysiological trait observed both in patients with autonomic neuropathy $[20,21]$ and in patients with increased UAE (urinary albumin excretion) [8]. The question of a possible causative role of autonomic neuropathy in the development of diabetic nephropathy has emerged [20, $22,23]$. The proposed pathophysiological mechanism is inappropriate renal vasodilatation permitting a more ready transmission of a higher night-time blood pressure to the glomeruli.
This hypothesis would be strengthened if normoalbuminuric patients at increased risk of progression to microalbuminuria proved to have disturbed autonomic function in combination with attenuated circadian blood pressure rhythm.

The aim of the present study was: i) to characterize a large group of normoalbuminuric IDDM patients according to UAE, 24-h ambulatory blood pressure, and sympathovagal balance; and ii) to determine whether disturbances in autonomic function and circadian blood pressure rhythm are detectable in normoalbuminuric patients at increased risk of progression to microalbuminuria.

\section{Subjects and methods}

Patients. 117 IDDM patients were consecutively recruited from outpatient clinics at our and two nearby hospitals. Patients had to be normoalbuminuric (UAE $<20 \mu \mathrm{g} / \mathrm{min}$ in at least two out of three overnight collections) and without other chronic diseases. None received (or had earlier received) antihypertensive or other medical treatment apart from insulin. UAE was measured by RIA and expressed as geometric mean of three overnight collections made within 1 week. $\mathrm{HbA}_{1 \mathrm{c}}$ was determined by HPLC (non-diabetic range 4.4-6.4\%). Blood glucose was determined (Reflolux II; Boehringer Mannheim, Mannheim, Germany) in association with autonomic testing.

Patients were classified according to participation in leisure-time physical activity as: passive (not participants), moderate (physical exercise once or twice a week), and active (Physical exercise more than twice a week). Tobacco consumption was graded as non-smokers (without daily use of tobacco for at least the last year), moderate smokers (less than 15 cigarettes per day) and heavy smokers (More than 15 cigarettes per day). Five patients smoking one packet of pipe tobacco per week were classified as moderate smokers.

The study was approved by the local ethics committee and patients gave their written informed consent.

A utonomic testing. According to written and oral instructions, patients had to refrain from smoking, eating, and drinking $2 \mathrm{~h}$ before the examination which took place in a quiet room with subdued light, with none other than the laboratory technician who performed the examination present. Patients rested in the supine position for $15 \mathrm{~min}$ breathing quietly at their normal respiration rate and afterwards $\mathrm{RR}$ intervals were measured using an on-line telemetrical transmitter (VariaPulse TF3; Sima Media Olomouc [24]). Short-term power spectral analysis was obtained in three positions (supine-standing-supine) each of at least $5 \mathrm{~min}$, resulting in three times 256 artifact-free heart beats. In addition to automatic filtering (using a recognition algorithm), each data set was visually scrutinized for ventricular ectopic beats. Frequent ventricular extrasystoles made power spectral analysis impossible in two patients $(1.7 \%)$. In the calculations a modified fast Fourier transformation was used (Coarse-graining) which allows extraction of a broadband non-harmonic 'noise', contaminating particularly the lower frequencies (1/f component) [25]. Low frequency (LF; $0.05-0.15 \mathrm{~Hz}$ ) and high frequency (HF; $0.15-0.50 \mathrm{~Hz}$ ) components were determined and expressed as $\ln \mathrm{ms}^{2}$. Coefficient of component variance (CCV; square root of power/mean RR) was calculated for the two components. This parameter accounts for a possible impact of the mean RR level on the 
Table 1. Clinical characteristics

\begin{tabular}{|c|c|c|c|c|}
\hline & All patients $(n=117)$ & $\mathrm{UAE}>4.2 \mu \mathrm{g} / \mathrm{min}(\mathrm{n}=59)$ & $\mathrm{UAE}<4.2 \mu \mathrm{g} / \mathrm{min}(\mathrm{n}=58)$ & $\mathrm{p}$ value \\
\hline $\begin{array}{l}\text { UAE }(\mu \mathrm{g} / \mathrm{min}) \\
\text { geometric mean } \times / \div \text { tolerance factor }\end{array}$ & $4.4 \times / \div 1.7$ & $6.6 \times / \div 1.4$ & $2.9 \times / \div 1.4$ & NR \\
\hline Age (years) & $38 \pm 9.6$ & $38 \pm 10.2$ & $38 \pm 9.0$ & NS \\
\hline Duration (years) & $18.6 \pm 10.1$ & $18.7 \pm 9.8$ & $18.5 \pm 10.5$ & NS \\
\hline Gender (\% male) & $45 \%$ & $39 \%$ & $52 \%$ & NS \\
\hline $\operatorname{BMI}\left(\mathrm{kg} / \mathrm{m}^{2}\right)$ & $23.9 \pm 2.6$ & $24.1 \pm 3.0$ & $23.7 \pm 2.2$ & NS \\
\hline $\mathrm{HbA}_{1 \mathrm{c}}(\%)$ & $8.4 \pm 1.1$ & $8.6 \pm 1.2$ & $8.2 \pm 1.0$ & 0.03 \\
\hline Blood glucose $(\mathrm{mmol} / \mathrm{l})$ & $10.8 \pm 5.6$ & 11. \pm 5.6 & $10.2 \pm 5.6$ & NS \\
\hline $\begin{array}{l}\text { Smoking status (\%) } \\
\text { Non-smoking - moderate - heavy }\end{array}$ & $69-8-23$ & $68-7-25$ & $70-9-21$ & NS \\
\hline $\begin{array}{l}\text { Physical activity (\%) } \\
\text { Not active - moderate - active }\end{array}$ & $66-28-6$ & $71-22-7$ & $61-33-6$ & NS \\
\hline
\end{tabular}

(mean $\pm \mathrm{SD}$, except when indicated)

NR: Not relevant. NS: not significant $p>0.25$

amplitude of the HF and LF component [18]. In addition MSSD (mean square of successive R-R differences) was calculated. Reproducibility of spectral power data was assessed in 27 healthy control subjects: The intra-individual coefficient of variation of two measurements performed within 1 week was for power LF: $15.9 \%$, and for power HF $11.3 \%$.

Three cardiovascular reflex tests were also performed: heart rate variation to deep breathing (inspiration/expiration difference, average of two determinations), heart rate response to standing up (30:15 ratio), and blood pressure response to standing up. The tests were performed and evaluated in accordance with the procedure described by Ewing et al. [26].

24-h blood pressure measurements and circadian blood pressure variation. Ambulatory blood pressure (AMBP) was measured by an oscillometric technique (Spacelabs 90207, Redmond, Wash., USA). Readings were obtained at 20-min intervals throughout $24 \mathrm{~h}$. Measurements were performed during a day with normal activities at home or at work. Individually reported sleeping times were implemented in the calculation of day and night-time blood pressure. No records with more than 2 missing hours were accepted, on this basis measurements from two patients $(1.7 \%)$ were excluded.

\section{Statistical analysis}

Before analysis UAE and power spectral data were log transformed to approximate normal distribution. Differences between the two groups were tested by Student's t test (continuous parameters) and chi-square test (discrete variables). Repeated measurements were analysed by repeated measurements ANOVA. Correlations were analysed using Pearsons test. Multiple regression analysis was performed by stepwise linear regression analysis, $\beta$ indicating the regression coefficient. Differences with $2 p$ greater than 0.05 were considered not significant (NS). Group results are given as mean $\pm \mathrm{SD}$, except for UAE, which is presented as geometric mean $\times 1 \div$ tolerance factor.

\section{Results}

Clinical characteristics of the patients are given in Table 1. Patients were divided according to the median UAE $(4.2 \mu \mathrm{g} / \mathrm{min})$, and the groups were similar regarding age, duration of diabetes, gender, BMI, level of physical activity, and cigarette smoking. Eight out of the 59 patients $(13.5 \%)$ in the higher UAE group had excretion rates exceeding $10 \mu \mathrm{g} / \mathrm{min}$. Blood glucose at the time of examination was similar in the two groups, whereas long-term glycaemic control was poorer in the group with UAE above the median and insulin consumption tended to be higher. Ambulatory blood pressure data are given in Table 2, and differences between the two groups with $95 \%$ confidence intervals are depicted in Figure 1. The day for the blood pressure measurement was characterized according to either working or day off work, the two groups were similar in this respect. Systolic and diastolic blood pressure were significantly higher in the group with UAE above the median for both 24-h, day, and night measurements. Clinic blood pressure (mean of three random zero measurements) confirmed these results $(124 \pm 16 / 83 \pm 9 \mathrm{mmHg}$ in the high normal UAE group compared to $117 \pm 11$ / $79 \pm 7 \mathrm{mmHg}$ in the low normal group, $p<0.01$ and $p<0.02$, respectively). There were no significant differences in heart rate between the two groups. As depicted in Figure 1 night differences were numerically bigger compared to day differences for both systolic and diastolic AMBP as well as heart rate, and diastolic night/day ratio tended to be higher (i.e. attenuated circadian rhythm) in the high normal UAE group $(82.5 \pm 6.2$ vs $80.6 \% \pm 5.4, p=0.08)$. Six patients $(5.2 \%)$ were non-dippers (five in the high-normal UAE group and one in the low-normal UAE group) when defined as systolic and diastolic nighttime drop of less than $10 \%$ [27]. These patients had 
Table 2. Ambulatory blood pressure data

\begin{tabular}{|c|c|c|c|c|}
\hline & & $\mathrm{UAE}>4.2 \mu \mathrm{g} / \mathrm{min}(\mathrm{n}=58)$ & $\mathrm{UAE}<4.2 \mu \mathrm{g} / \mathrm{min}(\mathrm{n}=57)$ & $p$ value \\
\hline $\begin{array}{l}\text { Type of day for AMBP (\%) } \\
\text { (working - half of each - day off) }\end{array}$ & & $38-4-58$ & $38-6-56$ & NS \\
\hline $\begin{array}{l}\text { Systolic } \\
\text { AMBP } \\
(\mathrm{mmHg})\end{array}$ & $\begin{array}{l}24 \mathrm{~h} \\
\text { Day } \\
\text { Night } \\
\text { Night/day ratio (\%) }\end{array}$ & $\begin{array}{l}125 \pm 10.1 \\
130 \pm 10.7 \\
114 \pm 10.7 \\
87.8 \pm 5.0\end{array}$ & $\begin{array}{l}120 \pm 8.4 \\
126 \pm 9.1 \\
109 \pm 8.8 \\
86.9 \pm 5.2\end{array}$ & $\begin{array}{l}<0.01 \\
0.02 \\
<0.01 \\
\text { NS }\end{array}$ \\
\hline $\begin{array}{l}\text { Diastolic } \\
\text { AMBP } \\
(\mathrm{mmHg})\end{array}$ & $\begin{array}{l}24 \mathrm{~h} \\
\text { Day } \\
\text { Night } \\
\text { Night/day ratio (\%) }\end{array}$ & $\begin{array}{l}76 \pm 7.2 \\
81 \pm 7.5 \\
67 \pm 7.8 \\
82.5 \pm 6.2\end{array}$ & $\begin{array}{l}74 \pm 5.1 \\
79 \pm 5.5 \\
63 \pm 5.4 \\
80.6 \pm 5.4\end{array}$ & $\begin{array}{l}0.02 \\
0.08 \\
<0.01 \\
0.08\end{array}$ \\
\hline $\begin{array}{l}\text { Heart } \\
\text { rate } \\
\text { (beats/min) }\end{array}$ & $\begin{array}{l}24 \mathrm{~h} \\
\text { Day } \\
\text { Night } \\
\text { Night/day ratio (\%) }\end{array}$ & $\begin{array}{l}77 \pm 9.1 \\
82 \pm 9.4 \\
67 \pm 10.1 \\
81.7 \pm 8.2\end{array}$ & $\begin{array}{l}76 \pm 9.1 \\
81 \pm 10.3 \\
65 \pm 9.6 \\
80.6 \pm 8.9\end{array}$ & $\begin{array}{l}\text { NS } \\
\text { NS } \\
\text { NS } \\
\text { NS }\end{array}$ \\
\hline
\end{tabular}

(mean \pm SD)

NS: Not significant $p>0.25$

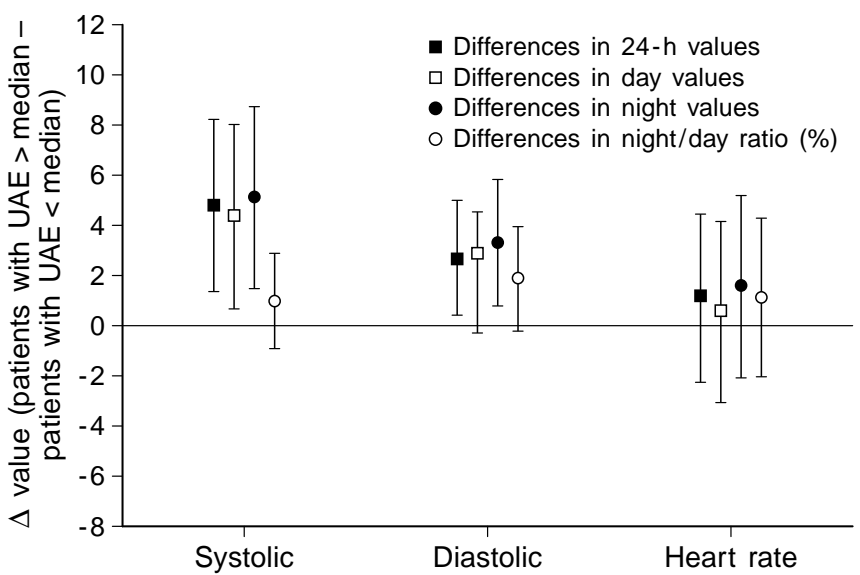

Fig. 1. $\Delta$ Systolic AMBP, $\Delta$ diastolic AMBP, $\Delta$ heart rate, and $\Delta$ night/day ratio (\%) between normoalbuminuric IDDM patients divided according to median UAE value $(4.2 \mu \mathrm{g} / \mathrm{min})$. Mean differences with $95 \%$ confidence intervals

similar age, duration, glycaemic status and gender composition compared to the dipping patients. The non-dippers had significantly reduced indices for autonomic function (power HF: $5.0 \pm 0.45$ vs $5.8 \pm 1.44$ ln $\mathrm{ms}^{2}(\mathrm{p}<0.01)$, power $\mathrm{LF}: 4.6 \pm 0.87$ vs $5.7 \mathrm{ln}$ $\mathrm{ms}^{2} \pm 1.3(p=0.02)$ compared to the dippers. Furthermore, the non-dippers had higher UAE $(6.4 \times 1 \div 1.46$ vs $4.3 \times 1 \div 1.7 \mu \mathrm{g} / \mathrm{min}, \mathrm{p}<0.05)$ and attenuated night/ day variation for heart rate $(88.6 \pm 10.3$ vs $80.8 \% \pm 8.3, p<0.03)$. In this material, the $10 \%$ percentile for circadian blood pressure variation was demarcated by a systolic and diastolic night drop of $12.2 \%$. With this cut off for reduced circadian variation, there were similar significant differences regarding autonomic indices, UAE, and night/day variation in heart rate (data not shown).

Table 3 shows the results of the autonomic tests in patients with low and high normal UAE. The group with UAE above the median had significantly reduced power $\mathrm{LF}$ and power $\mathrm{HF}$ (depicted in Fig. 2), $p=0.01$ and $p<0.04$. CCV-HF which accounts for differences in mean RR level was still significantly reduced in the high-normal UAE group. In addition, these patients had significantly reduced RR levels (faster heart rates), as well as reduced $\operatorname{MSSD}(p=0.05$ and $p=0.01)$. The conventional cardiovascular reflex tests revealed no statistically significant differences between the two groups, although indices were numerically reduced for the high normal UAE group (Table 4). Inspiration/expiration ratio and power HF were significantly correlated $(r=0.5$, $p<0.001$ ) and patients in the three groups of inspiration/expiration differences (abnormal/borderline/ normal) segregated with respect to power $\mathrm{HF}$ $\left(4.32 \pm 1.54, \quad 5.43 \pm 1.16\right.$, and $6.04 \pm 1.33 \mathrm{ln} \mathrm{ms}^{2}$, $\mathrm{p}<0.001$ ). Blood glucose (or $\mathrm{HbA}_{1 \mathrm{c}}$ ) and power $\mathrm{HF}$ or power LF were not associated $(r<-0.13$, $p>15 \%$ ).

Correlations between diurnal variation (heart rate and blood pressure), UAE, and autonomic indices are described in Table 5. Night/day ratio of heart rate and of arterial blood pressure were positively correlated. Night values for both heart rate and diastolic AMBP were inversely associated with HF and LF power and there were negative correlations between diurnal heart rate variation as well as diastolic AMBP and autonomic indices, i. e. attenuation in autonomic indices was associated with blunted diurnal variation (higher night/day ratios). There were no significant associations between UAE and autonomic indices. Correlations were significant between UAE and AMBP with the strongest positive association for night-time blood pressure leading to significant correlations between UAE and diastolic night/day ratio (Fig. 3).

Multiple, stepwise regression analysis was performed with diastolic night/day ratio as dependent variable. The following variables were entered as 
Table 3. Heart rate variability

\begin{tabular}{|c|c|c|c|c|c|}
\hline & & $\begin{array}{l}\text { UAE }>4.2 \mu \mathrm{g} / \mathrm{min} \\
(\mathrm{n}=58)\end{array}$ & $\begin{array}{l}\mathrm{UAE}<4.2 \mu \mathrm{g} / \mathrm{min} \\
(\mathrm{n}=57)\end{array}$ & p (between groups) & $\begin{array}{l}\text { ANOVA } \\
\text { (repeated measurements) }\end{array}$ \\
\hline Power HF (1n ms $\left.{ }^{2}\right)$ & $\begin{array}{l}\text { Supine } \\
\text { Standing } \\
\text { Supine }\end{array}$ & $\begin{array}{l}5.47 \pm 1.36 \\
4.15 \pm 1.44 \\
5.71 \pm 1.39\end{array}$ & $\begin{array}{l}6.10 \pm 1.43 \\
4.73 \pm 1.29 \\
6.23 \pm 1.36\end{array}$ & $\begin{array}{l}<0.02 \\
<0.03 \\
0.04\end{array}$ & $\begin{array}{l}\text { Group effect: } p=0.01 \\
\text { Postural effect: } p<0.01\end{array}$ \\
\hline Power LF (1n ms $\left.{ }^{2}\right)$ & $\begin{array}{l}\text { Supine } \\
\text { Standing } \\
\text { Supine }\end{array}$ & $\begin{array}{l}5.48 \pm 1.18 \\
5.53 \pm 1.36 \\
5.20 \pm 1.13\end{array}$ & $\begin{array}{l}5.80 \pm 1.41 \\
5.86 \pm 1.23 \\
5.79 \pm 1.19\end{array}$ & $\begin{array}{l}\text { NS } \\
\text { NS } \\
<0.01\end{array}$ & $\begin{array}{l}\text { Group effect: } p<0.04 \\
\text { Postural effect: } p=0.11\end{array}$ \\
\hline CCV LF (\%) & $\begin{array}{l}\text { Supine } \\
\text { Standing } \\
\text { Supine }\end{array}$ & $\begin{array}{l}1.97 \pm 1.1 \\
2.66 \pm 1.7 \\
1.70 \pm 1.0\end{array}$ & $\begin{array}{l}2.33 \pm 1.5 \\
3.00 \pm 1.9 \\
2.18 \pm 1.2\end{array}$ & $\begin{array}{l}\text { NS } \\
\text { NS } \\
0.01\end{array}$ & $\begin{array}{l}\text { Group effect: } p=0.08 \\
\text { Postural effect: } p<0.01\end{array}$ \\
\hline Centerfreq. High (mHz) & $\begin{array}{l}\text { Supine } \\
\text { Standing } \\
\text { Supine }\end{array}$ & $\begin{array}{l}231 \pm 47 \\
209 \pm 58 \\
238 \pm 51\end{array}$ & $\begin{array}{l}226 \pm 51 \\
209 \pm 47 \\
234 \pm 53\end{array}$ & $\begin{array}{l}\text { NS } \\
\text { NS } \\
\text { NS }\end{array}$ & $\begin{array}{l}\text { Group effect: NS } \\
\text { Postural effect: } p<0.01\end{array}$ \\
\hline Mean R-R (ms) & $\begin{array}{l}\text { Supine } \\
\text { Standing } \\
\text { Supine }\end{array}$ & $\begin{array}{l}916 \pm 108 \\
743 \pm 105 \\
921 \pm 116\end{array}$ & $\begin{array}{l}963 \pm 140 \\
759 \pm 116 \\
965 \pm 145\end{array}$ & $\begin{array}{l}0.04 \\
\text { NS } \\
0.07\end{array}$ & $\begin{array}{l}\text { Group effect: } p=0.05 \\
\text { Postural effect: } p<0.01\end{array}$ \\
\hline $\operatorname{MSSD}\left(1 \mathrm{n} \mathrm{ms}^{2}\right)$ & $\begin{array}{l}\text { Supine } \\
\text { Standing } \\
\text { Supine }\end{array}$ & $\begin{array}{l}6.54 \pm 1.15 \\
5.60 \pm 1.11 \\
6.77 \pm 1.29\end{array}$ & $\begin{array}{l}7.14 \pm 1.27 \\
5.98 \pm 1.08 \\
7.29 \pm 1.24\end{array}$ & $\begin{array}{l}0.01 \\
0.06 \\
0.03\end{array}$ & $\begin{array}{l}\text { Group effect: } p=0.01 \\
\text { Postural effect: } p<0.01\end{array}$ \\
\hline
\end{tabular}

(mean \pm SD)

Power HF, Power in the high frequency band $(0.15-0.50 \mathrm{~Hz})$;

Power LF, Power in the low frequency band $(0.05-0.15 \mathrm{~Hz})$;
$\mathrm{CCV}$, coefficient of component variance (square root of power/mean RR); MSSD, mean square of successive R-R differences. NS: Not Significant $(p>0.10)$

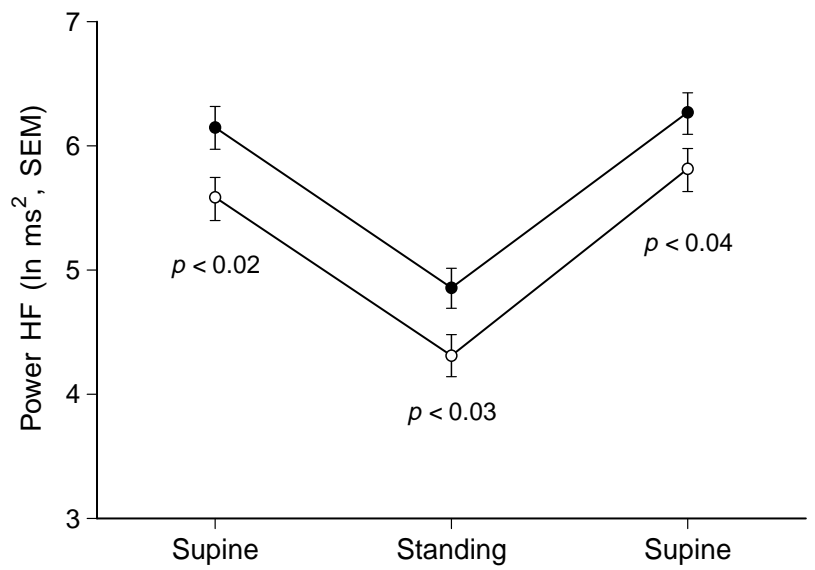

Fig. 2. Power HF $\left(\ln \mathrm{ms}^{2}\right)$ in 115 normoalbuminuric IDDM patients with UAE above $(\bigcirc)$, or below (O) median UAE $(4.2 \mu \mathrm{g} / \mathrm{min})$

possible predictors: gender, age, duration of diabetes, $\mathrm{UAE}, \mathrm{HbA}_{1 \mathrm{c}}$, smoking, power $\mathrm{LF}_{\text {standing, }}$, power $\mathrm{HF}_{\text {su- }}$ pine, type of day, and level of physical activity. Four variables were significantly associated with diastolic night/day ratio: type of day $(\beta=0.30)$, UAE $(\beta=0.23)$, Power $\mathrm{LF}_{\text {standing }}(\beta=-0.24)$, and level of physical activity $(\beta=0.20)$, adjusted $\mathrm{R}^{2:} 0.18$, ANO$\mathrm{VA}<0.001)$. Reduced power $\mathrm{LF}_{\text {standing, }}$, and high levels of UAE were associated with high night blood pressure, whereas days off and high physical activity were associated with relatively low daytime blood pressure and thus reduced diurnal variation.

\section{Discussion}

Our study is the first to address autonomic function (assessed by spectral analysis) and 24-h AMBP in a large number of well characterized, strictly normoalbuminuric IDDM patients. Longitudinal studies [4, 5, 28-30] have shown that high normal UAE, poor glycaemic control and perhaps high blood pressure are predictors of progression to microalbuminuria. We have found that normoalbuminuric patients at increased risk of progression (characterized by significant elevations in all the three progression parameters mentioned above) have a sympathovagal balance significantly different from normoalbuminuric patients with low UAE. The two groups were very similar in respect to all factors known to influence autonomic function (age, gender, diabetes duration, smoking, and level of physical activity). The data obtained extends the work of Mølgaard et al. [9, 10] who have shown that at the microalbuminuric stage a significant autonomic dysfunction is already present. Hansen et al. [31] have recently described a positive correlation between circadian variation of heart 
Table 4. Conventional cardiovascular reflex tests

\begin{tabular}{|c|c|c|c|}
\hline & $\mathrm{UAE}>4.2 \mu \mathrm{g} / \mathrm{min}(\mathrm{n}=59)$ & $\mathrm{UAE}<4.2 \mu \mathrm{g} / \mathrm{min}(\mathrm{n}=58)$ & $p$ value \\
\hline $\begin{array}{l}\text { Inspiratory-expiratory difference (beats/min) } \\
\text { [abnormal }(\leq 10) \text {-borderline(11-14)-normal }(\geq 5](\%)\end{array}$ & $\begin{array}{l}20.9 \pm 9.3 \\
{[14-18-68]}\end{array}$ & $\begin{array}{l}22.7 \pm 9.1 \\
{[9-11-80]}\end{array}$ & NS \\
\hline $\begin{array}{l}30: 15 \text { ratio } \\
{[\text { abnormal }(\leq 1.00) \text {-borderline(1.01-1.03)-normal }(\geq 1.04)](\%)}\end{array}$ & $\begin{array}{l}1.27 \pm 0.18 \\
{[2-0-98]}\end{array}$ & $\begin{array}{l}1.29 \pm 0.21 \\
{[7-5-88]}\end{array}$ & NS \\
\hline $\begin{array}{l}\text { Postural blood pressure change }(\mathrm{mmHg}) \\
{[\text { abnormal }(\geq 30) \text {-borderline }(11-29) \text {-normal }(\leq 10)](\%)}\end{array}$ & $\begin{array}{l}4.2 \pm 8.9 \\
{[0-3-97]}\end{array}$ & $\begin{array}{l}4.3 \pm 7.9 \\
{[0-3-97]}\end{array}$ & NS \\
\hline
\end{tabular}

$($ mean \pm SD)

NS, not significant $(p>0.10)$

Table 5. Correlations between AMBP data, spectral indices, and $\operatorname{UAE}(\mathrm{n}=115)$

\begin{tabular}{lll}
\hline & $r$ & $p$ value \\
\hline Heart rate N/D ratio & & \\
systolic N/D ratio & 0.31 & $<0.01$ \\
diastolic N/D ratio & 0.33 & $<0.01$ \\
MSSD & -0.23 & 0.01 \\
Power HF (supine) & -0.20 & 0.03 \\
Power LF (standing) & & $\mathrm{NS}$ \\
Night heart rate & & \\
MSSD & -0.31 & $<0.01$ \\
Power HF (supine) & -0.24 & $<0.01$ \\
Power LF (standing) & -0.25 & \pm 0.01 \\
Diastolic N/D ratio & & \\
UAE & 0.22 & 0.02 \\
MSSD & & $\mathrm{NS}$ \\
Power HF (supine) & & $\mathrm{NS}$ \\
Power LF (standing) & -0.22 & $<0.02$ \\
Diastolic Night AMBP $~$ & & \\
UAE & 0.27 & $<0.01$ \\
MSSD & & $\mathrm{NS}$ \\
Power HF (supine) & -0.19 & $<0.05$ \\
Power LF (standing) & -0.33 & $<0.01$ \\
\hline
\end{tabular}

$\mathrm{N} / \mathrm{D}$ ratio, night/day ratio, Power HF, power in the high frequency band $(0.15-0.50 \mathrm{~Hz})$, Power $\mathrm{HF}$, power in the low frequency band $(0.05-0.15 \mathrm{~Hz})$, MSSD, mean square of successive $R-R$ differences, NS, not significant $(p>0.10)$

rate and of blood pressure in IDDM patients with nephropathy and suggests a relative lack of sympathethic withdrawal as a possible explanation for nocturnal hypertension, although no specific measures of sympathovagal function were performed. Our data extend this finding to normoalbuminuric patients and furthermore we found significant negative correlations between more specific indices of autonomic function (power LF and MSSD) and night-time heart rate as well as night-time blood pressure, i. e. attenuation in autonomic indices is associated with blunted diurnal variation in both heart rate and arterial blood pressure.

As to the differentiation between parasympathethic and sympathethic function by spectral analysis, the latter is thought to be mediated through RR interval oscillations in the LF band in the upright position [16]. The technique for specific assessment of sympathethic activity is at its present stage, however still incomplete. Thus, the interpretation of the changes observed in our study is confined to combined paraand sympathetic disturbances. The combination of higher blood pressure and shorter mean RR intervals however, strongly suggests sympathetic overactivity in the putative high-risk group. Our data indicate that high normal UAE is accompanied by signs of autonomic dysfunction. Only longitudinal studies can reveal whether this represents coexistence of independent variables with a common background, or if autonomic disturbances play a pathogenetic role in the very early development of diabetic nephropathy $[20,22,23,32]$.

IDDM patients with autonomic neuropathy [20, 21] have an attenuated circadian BP rhythm with reduced night-time drop of blood pressure [20, 21]. The same is true for IDDM patients with increased UAE [8]. Recent data indicate that diabetic patients may have impaired circadian modulation of sympathovagal activity [19]. Lack of sympathethic withdrawal during sleep has been suggested as an important feature of nocturnal hypertension in IDDM patients with nephropathy [31]. Consequently, the question of a possible causative role of autonomic neuropathy in the development of diabetic nephropathy has been raised [20, 22, 23]. In our patients with high-normal UAE both blood pressure and heart rate elevations were greater numerically for the night period and diastolic night/day ratio tended to be higher. Furthermore, there was a significant correlation between UAE and diastolic night/day ratio and when dichotomizing patients into dippers and non-dippers, the non-dipping patients had significantly reduced indices of autonomic function, confirming that also in normoalbuminuric patients, attenuated circadian variation of blood pressure is associated with autonomic dysfunction.

The frequency of non-dippers was lower than reported in several other studies [27].The reason is probably twofold: The patients in our study were all normoalbuminuric and their reported sleeping times were used in the calculation of day and night-time blood pressure thus avoiding erroneously overestimating the fraction of patients with abnormal circadian variation [33]. The use of the 10th percentile for abnormal circadian blood pressure variation might 


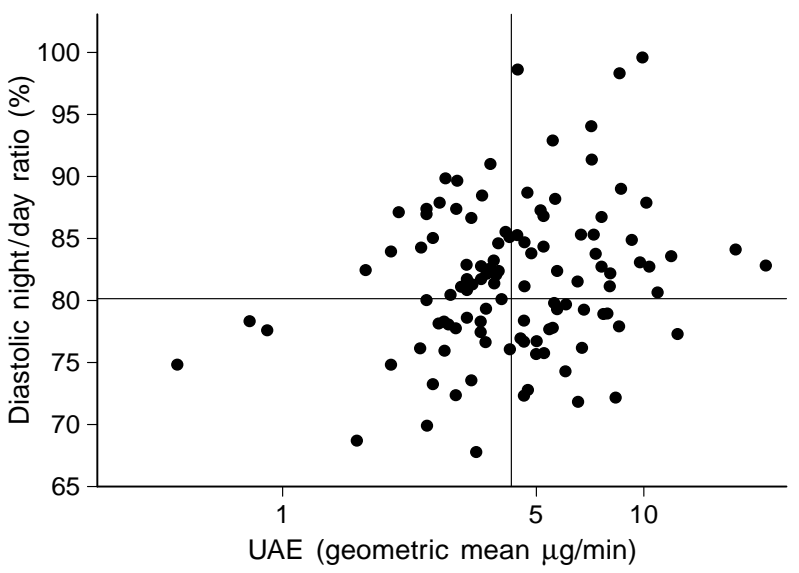

Fig. 3. Association between diastolic night/day ratio and UAE in 115 normoalbuminuric IDDM patients. Dotted lines indicate median values

be more appropriate when patient-reported sleeping times are used. Patients with diurnal variation below the 10th percentile had significantly reduced autonomic indices confirming the results mentioned above.

With power spectral analysis significant differences in autonomic function were revealed between patients with high-normal and low-normal UAE, as well as significant differences between non-dipping and dipping patients. These differences were not detectable by conventional tests, confirming that power spectral analysis is more sensitive than ordinary bedside tests to detect early autonomic changes $[9,14$, $34,35]$.

The combination of a poorer glycaemic status and a trend towards higher insulin consumption in patients with UAE above the median could suggest insulin resistance in this group, as has been demonstrated in microalbuminuric patients compared to normoalbuminuric patients [36]. In addition, higher insulin requirement has been described in normoalbuminuric IDDM patients later progressing to microor macroalbuminuria [37]; however, we did not perform specific evaluations of this (e.g. glucose clamps).

Patients in this study were selected with regard to UAE (strictly normoalbuminuria) and blood pressure (no present or earlier antihypertensive treatment). Even so, we found clear associations between albumin excretion and blood pressure as well as autonomic indices. Our findings stress that albumin excretion should be considered as a continuum; although demarcation in the clinical situation is an operational necessity, changes both in blood pressure and autonomic function are demonstrable before transition to microalbuminuria, provided methods with sufficient sensitivity are implemented.

In conclusion, when comparing normoalbuminuric IDDM patients at increased risk of progression to microalbuminuria (UAE above the median) with putative low-risk patients (UAE below the median value), we found significantly higher blood pressure in combination with significant differences in sympathovagal balance and higher $\mathrm{HbA}_{1 \mathrm{c}}$ in the group with high normoalbuminuria. Autonomic dysfunction may interact with poor glycaemic control and blood pressure elevation in determining nephropathy risk in IDDM patients.

A cknowledgements. We are grateful to Dr. H. Mølgaard for helpful criticism of the manuscript and to M. Møller for excellent technical assistance. The Danish Diabetes Association, The Novo Nordisk foundation, and The Sehested Hansen foundation are acknowledged for financial support.

\section{References}

1. Viberti, GC, Hill RD, Jarrett RJ, Argyropoulos A, Mahmud U, Keen H (1982) Microalbuminuria as a predictor of clinical nephropathy in insulin-dependent diabetes mellitus. Lancet I:1430-1432

2. Mogensen CE, Christensen CK (1984) Predicting diabetic nephropathy in insulin-dependent patients. N Engl J Med 311: 89-93

3. Parving H-H, Oxenbøll B, Johansen K, Svendsen PA, Christiansen JS, Andersen AR (1982) Early detection of patients at risk of developing diabetic nephropathy: a longitudinal study of urinary albumin excretion. Acta Endocrinol Copenh 100: 500-505

4. Microalbuminuria Collaborative Study Group United Kingdom (1993) Risk factors for development of microalbuminuria in insulin dependent diabetic patients: a cohort study. BMJ 306: 1235-1239

5. Poulsen PL, Hansen KW, Mogensen CE (1994) Ambulatory blood pressure in the transition from normo- to microalbuminuria. A longitudinal study in IDDM patients. Diabetes 43: 1248-1253

6. Mathiesen, ER, Ronn B, Storm B, Foght H, Deckert T (1995) The natural course of microalbuminuria in insulindependent diabetes: a 10-year prospective study. Diabet Med 12: 482-487

7. Hansen KW, Christensen CK, Andersen PH, Pedersen MM, Christiansen JS, Mogensen CE (1992) Ambulatory blood pressure in microalbuminuric type 1 diabetic patients. Kidney Int 41: 847-854

8. Hansen KW, Mau Pedersen M, Marshall SM, Christiansen JS, Mogensen CE (1992) Circadian variation of blood pressure in patients with diabetic nephropathy. Diabetologia 35: 1074-1079

9. Mølgaard H, Christensen PD, Sørensen KE, Christensen CK, Mogensen CE (1992) Association of 24-h cardiac parasympathetic activity and degree of nephropathy in IDDM patients. Diabetes 41: 812-817

10. Mølgaard, H, Christensen PD, Hermansen K, Sørensen KE, Christensen CK, Mogensen CE (1994) Early recognition of autonomic dysfunction in microalbuminuria: significance for cardiovascular mortality in diabetes mellitus? Diabetologia 37: 788-796

11. Østerby R, Bangstad HJ, Nyberg G, Walker JD, Viberti GC (1995) A quantitative ultrastructural study of juxtaglomerular arterioles in IDDM patients with micro- and normoalbuminuria. Diabetologia 38: 1320-1327 
12 Bangstad, HJ, Østerby R, Dahl Jørgensen K et al. (1993) Early glomerulopathy is present in young, type 1 (insulindependent) diabetic patients with microalbuminuria. Diabetologia 36: 523-529

13. Akselrod S, Gordon D, Ubel FA, Shannon DC, Barger AC, Cohen RJ (1981) Power spectrum analysis of the heart rate fluctuation: a quantitative probe of beat-to-beat cardiovascular control. Science 213: 220-222

14. Ewing DJ, Neilson JM, Shapiro CM, Stewart JA, Reid W (1991) Twenty four hour heart rate variability: effects of posture, sleep, and time of day in healthy controls and comparison with bedside tests of autonomic function in diabetic patients. Br Heart J 65: 239-244

15. Malpas SC, Maling TJB (1990) Heart-rate variability and cardiac autonomic function in diabetes. Diabetes 39: 11771181

16. Pomeranz B, Macaulay RJ, Caudill MA et al. (1985) Assessment of autonomic function in humans by heart rate spectral analysis. Am J Physiol 248:H151-H153

17. Furlan R, Guzzetti S, Crivellaro W et al. (1990) Continuous 24-hour assessment of the neural regulation of systemic arterial pressure and RR variabilities in ambulant subjects. Circulation 81: 537-547

18. Hayano J, Sakakibara Y, Yamada A et al. (1991) Accuracy of assessment of cardiac vagal tone by heart rate variability in normal subjects. Am J Cardiol 67: 199-204

19. Bernardi L, Ricordi L, Lazzari P et al. (1992) Impaired circadian modulation of sympathovagal activity in diabetes. A possible explanation for altered temporal onset of cardiovascular disease. Circulation 86: 1443-1452

20. Monteagudo, PT, Nóbrega JC, Cezarini PR et al. (1996) Altered blood pressure profile, autonomic neuropathy and nephropathy in insulin dependent diabetic patients. Euro J Endocrinol 135: 683-688

21. Spallone V, Gambardella S, Maiello MR, Barini A, Frontoni S, Menzinger G (1994) Relationship between autonomic neuropathy, 24-h blood pressure profile, and nephropathy in normotensive IDDM patients. Diabetes Care 17: 578584

22. Lilja B, Nosslin B, Bergstrom B, Sundkvist G (1985) Glomerular filtration rate, autonomic nerve function, and orthostatic blood pressure in patients with diabetes mellitus. Diabetes Res 2: 179-181

23. Winocour PH, Dhar H, Anderson DC (1986) The relationship between autonomic neuropathy and urinary sodium and albumin excretion in insulin-treated diabetics. Diabet Med 3: 436-440

24. Sallinger J, Vychodil R, Pumprla J et al. (1995) Telemetric computer-aided system for non-invasive examination of heart rate variability, type VariaPulse TF3. Comput Cardiol IEEE Proc:437-440

25. Yamamoto Y, Hughson RL (1991) Coarse-graining spectral analysis: new method for studying heart rate variability. J Appl Physiol 71: 1143-1150

26. Ewing DJ, Martyn CN, Young RJ, Clarke BF (1985) The value of cardiovascular autonomic function tests: 10 years experience in diabetes. Diabetes Care 8: 491-498

27. Verdecchia P, Schillaci G, Porcellati C (1991) Dippers versus non-dippers. Hypertension 9[Suppl 8]:S42-S44

28. The Diabetes Control and Complication Trial Research Group (1993) The effect of intensive treatment of diabetes on the development and progression of long-term complications in insulin-dependent diabetes mellitus. N Engl J Med 329: 977-986

29. Coonrod BA, Ellis D, Becker DJ et al. (1993) Predictors of Microalbuminuria in Individuals with IDDM. Pittsburg Epidemiology of Diabetes Complication Study. Diabetes Care 16: 1376-1383

30. Rudberg S, Ullman E, Dahlquist G (1993) Relationship between early metabolic control and the development of microalbuminuria - a longitudinal study in children with type 1 (insulin-dependent) diabetes mellitus. Diabetologia 36: 1309-1314

31. Hansen HP, Rossing P, Tarnow L, Nielsen FS, Jensen B, Parving H-H (1996) Circadian rhythm of arterial blood pressure and albuminuria in diabetic nephropathy. Kidney Int 50: 579-585

32. Spallone V, Maiello MR, Cicconetti E, Barini A, Gambardella S, Menzinger G (1996) Role of autonomic neuropathy in development of nephropathy and hypertension in IDDM patients. Diabetologia [Suppl] 1:A255

33. Hansen KW, Pedersen MM, Christiansen JS, Mogensen CE (1993) Diurnal blood pressure variations in normoalbuminuric type 1 diabetic patients. J Intern Med 234: 175-180

34. Malpas SC, Maling TJ (1990) Heart-rate variability and cardiac autonomic function in diabetes. Diabetes 39: 11771181

35. Weston PJ, Panerai RB, McCullough A et al. (1996) Assessment of baroreceptor-cardiac reflex sensitivity using time domain analysis in patients with IDDM and the relation to left ventricular mass index. Diabetologia 39: 13851391

36. Yip J, Mattock MB, Morocutti A, Sethi M, Trevisan R, Viberti GC (1993) Insulin resistance in insulin-dependent diabetic patients with microalbuminuria. Lancet 342: 883-887

37. Forsblom CM, Groop PH, Ekstrand A, Groop LC (1992) Predictive value of microalbuminuria in patients with insulin-dependent diabetes of long duration. BMJ 305: 10511053 